Document downloaded from:

http://hdl.handle.net/10251/83426

This paper must be cited as:

Payri Marín, R.; Gimeno García, J.; Cuisano, J.; Arco, J. (2016). Hydraulic Characterization of Diesel Engine Single-Hole Injectors. Fuel. 180:357-366. doi:10.1016/j.fuel.2016.03.083.

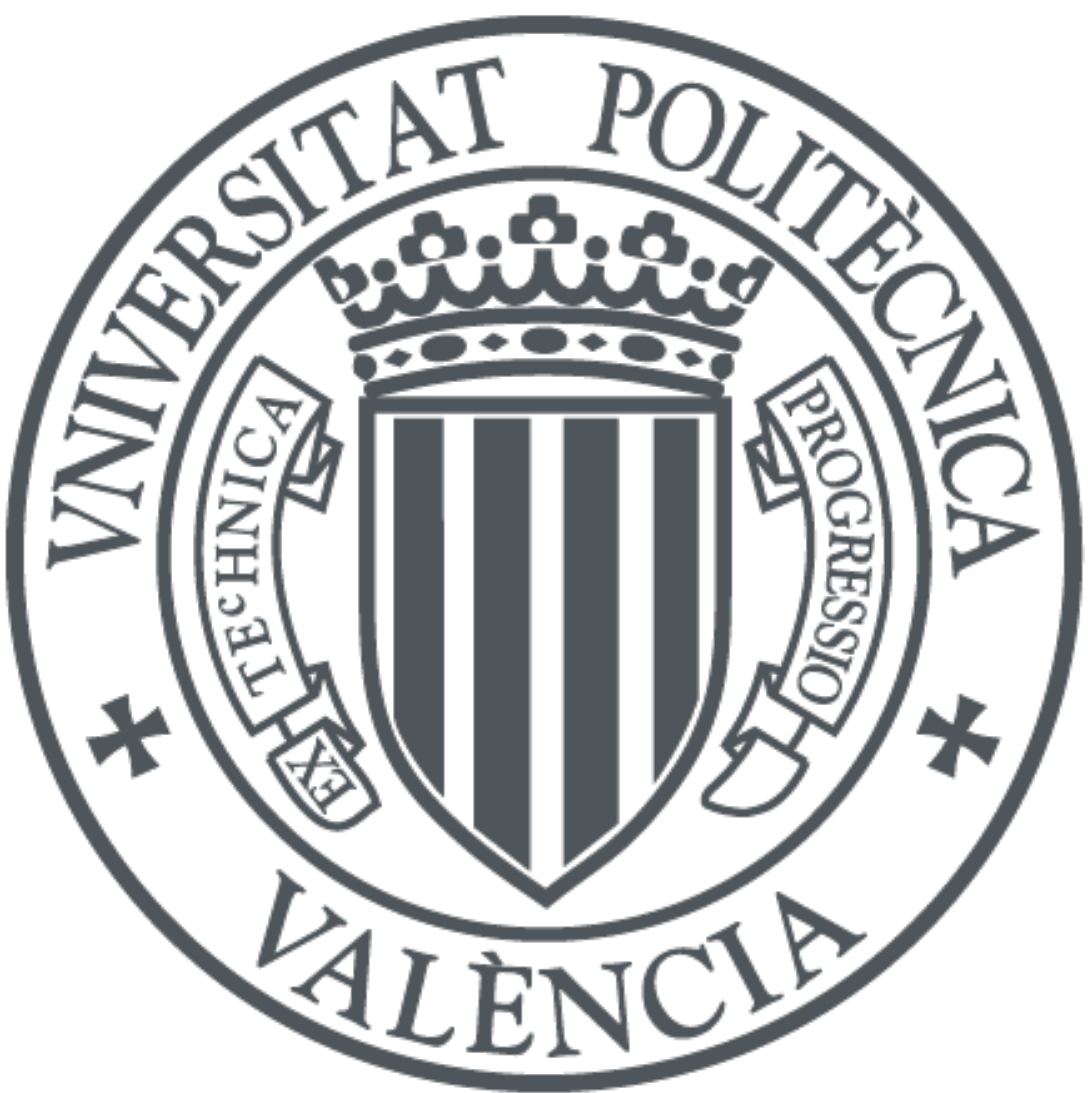

The final publication is available at

http://doi.org/10.1016/j.fuel.2016.03.083

Copyright Elsevier

Additional Information 


\title{
Hydraulic characterization of diesel engine single-hole injectors
}

\author{
R. Payri ${ }^{\mathrm{a}, *}$, J. Gimeno ${ }^{\mathrm{a}}$, J. Cuisano ${ }^{\mathrm{b}}$, J. Arco $^{\mathrm{c}}$ \\ ${ }^{a}$ CMT-Motores Térmicos, Universitat Politècnica de València, Camino de Vera s/n, E-46022 Spain. \\ ${ }^{b}$ Pontificia Universidad Católica del Perú, Lima, Peru. \\ ${ }^{c}$ KTH Royal Institute of Technology, Stockholm, Sweden.
}

\begin{abstract}
Due to world trend on the emission regulations and greater demand of fuel economy, the research on advanced diesel injector designs is a key factor for the next generation diesel engines. For that reason, it is well established that understanding the effects of the nozzle geometry on the spray development, fuelair mixing, combustion and pollutants formation is of crucial importance to achieve these goals. In the present research, the influence of the injector nozzle geometry on the internal flow characteristics is studied. For this purpose, ten single-hole diesel injectors differing in the orifices degree of conicity (five cylindrical, five conical) but with similar nozzle flow capacity have been characterized geometrically (measurements of nozzle outlet section) and hydraulically. The mass flow and momentum flux rates have been measured for a wide range of experimental conditions. Special attention is given to study the cavitation phenomenon since the cylindrically-shaped nozzle orifices are expected to propitiate cavitation due to abrupt changes in flow direction. The study has been carried out with two different fuels: n-dodecane and commercial diesel, thereby the effect of the fuel properties is also analyzed. The results show that the measured nozzle outlet diameters are higher than the nominal specification for both nozzle types. As expected, the onset of cavitation on the cylindrical nozzles has been identified causing a reduction on the injected mass for all tested conditions. The effective diameter for the cylindrical nozzles have been found to be around $175 \mu \mathrm{m}$ (geometrical diameter $\approx 212 \mu \mathrm{m}$ ) and around $185 \mu \mathrm{m}$ (geometrical diameter $\approx 191 \mu \mathrm{m}$ ) for the conical ones. Finally, the higher density of diesel with respect to n-Dodecane have resulted on mass flow rates around $8 \%$ over the n-dodecane values for the same test conditions.
\end{abstract}

Keywords: Diesel, n-Dodecane, Cavitation, Injection rate, Spray momentum, Hydraulic characterization

\section{Introduction}

In order to develop computational models to predict the combustion process in diesel engines, deep knowledge of the injection process and the spray development in the combustion chamber is required to reduce uncertainties and therefore improve the accuracy of the predictive methods [1].

With a view to promoting international collaboration among experimental and computational researchers within the engine combustion field, the Engine Combustion Network (ECN) [2] was created, addressing the research to reference test conditions and identifying priorities for future researches. Hardware and operating conditions with same specification and tightly controlled boundary conditions (e.g. "Spray A": $900 \mathrm{~K}, 60$ bar,

Cite as:

Payri, R., Gimeno, J., Cuisano, J. and Arco, J., "Hydraulic characterization of diesel engine single-hole injectors", Fuel, (2016), Vol. 180, pp. 357-366, doi:10.1016/j.fuel.2016.03.083

* Corresponding author. Tel.: +34963879658; fax.: +34963877659

Email address: rpayri@mot.upv.es (R. Payri) 


\section{Nomenclature}

ET Energizing time. Electric command sent to the solenoid injector

$k$-factor Nozzle orifice conicity factor

Re Reynolds number

$C_{a}$ Area coefficient

$C_{d}$ Orifice discharge coefficient

$C_{v}$ Velocity coefficient

$p_{b}$ Back pressure

$p_{i}$ Fuel injection pressure

$u_{e f f}$ Effective injection velocity

$22.8 \mathrm{~kg} / \mathrm{m}^{3}, 15 \%$ oxygen $\left.[3,4]\right)$ have been used to develop highly leveraged data sets appropriate to engines [5].

The present paper is divided into six sections, starting with this introduction. After that, the new ECN injectors used for the study are presented followed by a summary of the physical properties of the fuels employed. Information regarding the experimental setup is given in section 4 and the obtained results are presented and discussed in sections 5 and 6 .

\section{ECN Spray C and Spray D nozzles}

Regarding the injectors used for this study, the ECN group has recently acquired ten large-nozzle singlehole diesel injectors from Bosch. The solenoid-activated injector specifications pertain to modern advanced injection systems with 2200 bar nominal pressure rating (2500 bar capable).

The injectors incorporate an axial single-hole nozzle to facilitate optical diagnostics of the spray [6]. As can be seen in Table 1, ECN group has classified the ten injectors in "Spray C" or "Spray D", according to similar nominal parameters of their respective nozzles.

Table 1: Nominal specification of the ECN large-nozzle single-hole diesel injectors[2]

\begin{tabular}{ccc}
\hline \multicolumn{2}{c}{ Specifications for Spray C \& D of the Engine Combustion Network } \\
\hline & Spray C & Spray D \\
\hline Common rail fuel injector & Bosch $3-22$ & Bosch $3-22$ \\
Injentor nominal diameter & $200 \mu \mathrm{m}$ & $186 \mu \mathrm{m}$ \\
k-factor & $\mathrm{k}=0$ & $\mathrm{k}=1.5$ \\
Nozzle shaping & $5 \%$ hydroerosion & Hidroerosion to $C_{d}=0.86$ \\
Flow with 10 MPa pressure drop & $200 \mathrm{~cm}^{3} / \mathrm{min}$ & $228 \mathrm{~cm}^{3} / \mathrm{min}$ \\
Number of holes & $1($ single hole $)$ & $1($ single hole) \\
\hline
\end{tabular}

The five "Spray C" nozzles have a nominal outlet diameter of $0.2 \mathrm{~mm}$. The orifice is cylindrical ( $k-$ factor equal to zero) with $5 \%$ of hydro-grinding to relatively smooth the contours of the orifice (see Figure 1).

With respect to the five "Spray D" nozzles, these have a nominal outlet diameter of $0.180 \mathrm{~mm}$. The orifice is conical with a $k$-factor of 1.5. Similarly, hydro-grinding has been performed to get a nominal $C_{d}=0.86$ at the specified flow number. The use of convergent nozzles is justified precisely because the convergence of the holes will prevent the onset of the cavitation phenomenon [7]. Moreover, in recent years, 


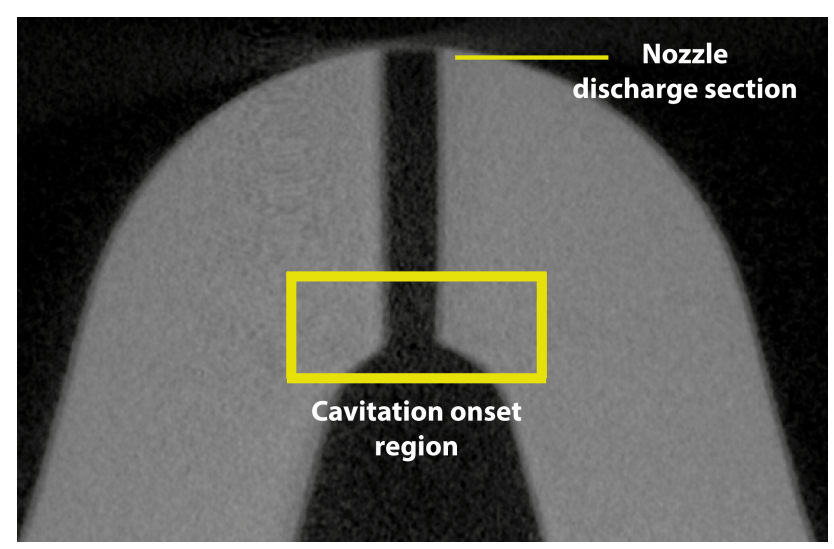

Figure 1: X-ray tomography of a Spray C nozzle indicating the region where the boundary layer separation occurs [2].

engine manufacturers are opting for this type of nozzles instead of cavitating nozzles with cylindrical holes $[8]$.

\section{Fuel characterization}

In order to perform rate of injection measurements (ROI) via injection rate discharge curve indicator (IRDCI), the speed of sound through the fluid at the operating temperature and pressure conditions has to be known [9]. Additionally, the density and viscosity at the orifice exit conditions are required to calculate the mass flow rate and Reynolds number. For those reasons, the fuels employed for the tests need to be completely characterized to assure the reliability of the results.

At first instance, the fuel employed for the tests has been n-dodecane. It is a fluorescence-free diagnostics fuel chosen by the ECN working group in order to enable a complete specification of the chemical and physical properties of the fuel [10].

Secondly, with the aim of simulating the real environment where the injectors operate, commercial diesel fuel is used in the comparison (in Spain share of biodiesel in commercial diesel fuel is variable with an average of $1.5 \%$ [11]). An analysis of the physical properties that are of interest for this study has been performed at CMT for the diesel fuel used in the experiments.

The first test consisted on the determination of the kinematic viscosity of the fuel.

The second parameter used in the calculations of the variables derived from the ROI measurements is fuel density. The standard methodology to obtain the density curve of a fuel, and the one used in this report, is explained in [12].

The effects of temperature on fuel density and viscosity obtained are shown in Figure 2.

\section{Experimental setup}

The injection system that has been implemented for the study consists of commercially available components, namely a high pressure volumetric pump driven by an electric motor and a common-rail coupled with a pressure sensor to ultimately determine the discharge pressure. The system is capable of delivering fuel up to $250 \mathrm{MPa}$.

The rail has a volume of $22 \mathrm{~cm}^{3}$ and is connected to the injector through a tube with a length of $20 \mathrm{~cm}$ and an internal diameter of $3 \mathrm{~mm}$. The injector driver signal is constituted of a current pulse that rises up to $25 \mathrm{~A}$ for $0.1 \mathrm{~ms}$, remains at $15 \mathrm{~A}$ for $0.45 \mathrm{~ms}$ as initial hold, and ends with $11 \mathrm{~A}$ as final hold. A constant voltage of $27 \mathrm{~V}$ is supplied to the solenoid.

Mass flow rate and momentum measurements are used to hydraulically characterize the injectors. The measurements of rate of injection (ROI) were carried out in an Injection Rate Discharge Curve Indicator 


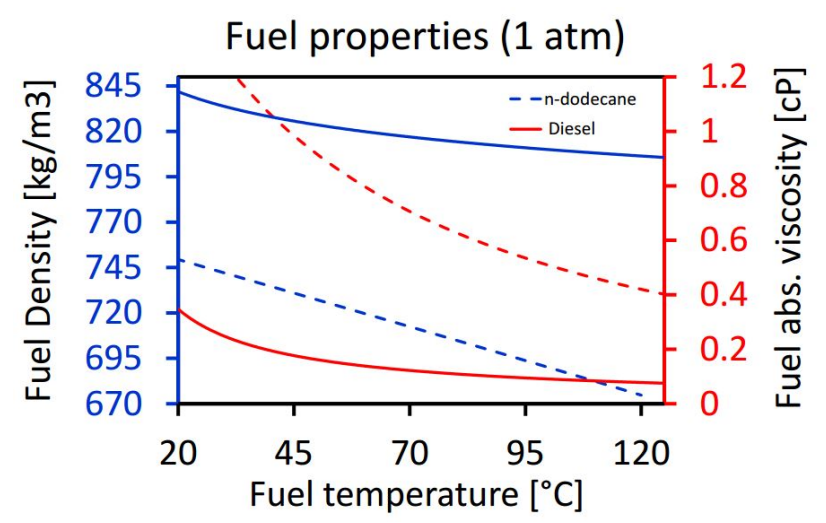

Figure 2: Fuel temperature effect on density and absolute viscosity for both utilized fuels (atmospheric pressure)

(IRDCI) which uses the Bosch method [9]. The spray momentum rate tests were performed using a specific device designed at CMT - Motores Térmicos which is fully described in reference [13].

The recorded ROI signal was passed through a charge amplifier and then recorded by an analogue to digital converter working at $100 \mathrm{kHz}$ acquisition rate. This signal is recorded together with the instantaneous rail pressure and the intensity of the energizing signal. For each test condition, 50 injection events were recorded in order to obtain a reliable indication of the average value and the shot-to-shot dispersion [9].

\subsection{Test matrix}

The experimental campaign was divided in two rounds based on the fuel employed for the experiments. For the first campaign, the experiments were performed using n-dodecane and the ECN standard experimental conditions called "Spray A" which are defined at [2] and are relevant for the diesel sprays. In this first round, all ten ECN injector were available at CMT - Motores Térmicos and a matrix consisting of 6 operating conditions and 2 energizing times was tested for both ROI and momentum flux rate measurements. For momentum flux rate measurements, 3 operating points were chosen. Table 2 summarizes the tests with n-dodecane fuel.

Table 2: Experimental test matrix performed with n-Dodecane fuel

\begin{tabular}{cc}
\hline Fuel & n-Dodecane \\
Injectors tested & 003C-034C-037C-044C-105C \\
& 103D-104D-133D-134D-135D \\
\hline & Rate of injection \\
$\boldsymbol{E} \boldsymbol{T}[\mathrm{ms}]$ & $1.0-2.5$ \\
$\boldsymbol{p}_{\boldsymbol{i}}[\mathrm{MPa}]$ & $50-100-150$ \\
$\boldsymbol{p}_{\boldsymbol{b}}[\mathrm{MPa}]$ & $2-6$ \\
$\boldsymbol{E} \boldsymbol{T}[\mathrm{ms}]$ & Rate of momentum \\
\cline { 2 - 2 } $\boldsymbol{p}_{\boldsymbol{i}}[\mathrm{MPa}]$ & 2.5 \\
$\boldsymbol{p}_{\boldsymbol{b}}[\mathrm{MPa}]$ & $50-100-150$ \\
\hline
\end{tabular}

For these hydraulic measurements, the temperature of the discharge section is close to that of the ambient (around $293 \mathrm{~K}$ ) and the body of the injector is temperature-controlled to match that measured during vessel experiments to $70^{\circ} \mathrm{C}(343 \mathrm{~K})$.

After the first experimental campaign, three "Spray C" and three "Spray D" injectors were distributed to other ECN institutions for comparison and validation of the obtained results and further research. The remaining four injectors (2 "Spray C" and 2 "Spray D") are employed for the second testing campaign at CMT. 
This second round of measurements was undertaken using commercial diesel fuel and covering a wider range of operating conditions with the aim of studying the cavitation phenomenon and the impact on flow characteristics at nozzle orifice outlet. In this case, 28 operating points were chosen for the ROI measurements and 20 points for momentum flux rate. The operating points are summarized in Table 3

Table 3: Experimental test matrix performed with Diesel fuel

\begin{tabular}{cc}
\hline Fuel & Diesel \\
Injectors tested & 003C-044C \\
& Rate of injection $-135 \mathrm{D}$ \\
\hline $\boldsymbol{E} \boldsymbol{T}[\mathrm{ms}]$ & 2.5 \\
$\boldsymbol{p}_{\boldsymbol{i}}[\mathrm{MPa}]$ & $50-100-150-200$ \\
$\boldsymbol{p}_{\boldsymbol{b}}[\mathrm{MPa}]$ & $2.0-5.3-6.0-8.5-9.7-12.0-14.0$ \\
$\boldsymbol{E} \boldsymbol{T}[\mathbf{m s}]$ & Rate of momentum \\
\cline { 2 - 2 } $\boldsymbol{p}_{\boldsymbol{i}}[\mathbf{M P a}]$ & $50-100-150-200$ \\
$\boldsymbol{p}_{\boldsymbol{b}}[\mathrm{MPa}]$ & $2.0-5.3-6.0-8.5-9.7$ \\
\hline
\end{tabular}

\section{Results and discussion}

This section presents the results of the experimental campaign performed to a new pool of standard ECN injectors and evaluates the impact of the nozzle geometry on the hydraulic performance and cavitation phenomenon.

\subsection{Rate of injection results}

In general, very similar mass flow rate and momentum flux rate curves are obtained in each group of injectors ("Spray C" and "Spray D"). All figures in this section display average curves of 50 and 25 injection events for ROI measurements and momentum flux rate respectively. As can be seen in Figure 3, "Spray C" and "Spray D" injectors show the same hydraulic delay [14] (i.e., the injector opens at a same time from the electrical signal reception). With respect to the opening and closing phases, both injector types show a fast behavior with equal opening slopes; however, the profiles show a slight difference during the closing times.

During the steady state period, as expected given the results of the nozzle geometry measurements, the ROI results seem to scale with the actual outlet diameters reported in Table 4. Although the two nozzle types used have similar flow capacity definition in terms of Bosch flow number, and despite outlet diameters of the nozzles mounted in the "Spray D" injectors being smaller than of the "Spray C" injectors, the total amount of injected mass is higher for "Spray D" nozzles. The main reason for that seems to be the onset of cavitation on "Spray C" nozzles as explained later on.

As displayed in Table 4 and Figure 3, the time-averaged values of the steady state mass flow rates (average between approximately 1.2 and $2.7 \mathrm{~ms}$ ) are $11.71 \mathrm{~g} / \mathrm{s}$ and $10.06 \mathrm{~g} / \mathrm{s}$ respectively for "Spray D" and "Spray C" injectors; and the average injected fuel mass values are $51.3 \mathrm{mg} /$ injection and $44.6 \mathrm{mg} /$ injection for D and C. Besides, injectors 104D and $044 \mathrm{C}$ have the lower values of steady state mass flow rate and the injected mass in their respective groups.

\subsubsection{Influence of back pressure}

The fuel inside the IRDCI device is pressurized by filling with nitrogen an adjacent cavity which is separated by a membrane. In that way, an increase in back pressure is equivalent to an increase in density. Thus, different chamber pressures are compared in Figure 4. In general, higher injection rates are obtained for lower back pressures as can be seen in Figure 4. However, this trend is mostly seen for low injection pressures where the pressure drop between the nozzle and the discharge chamber is small. 


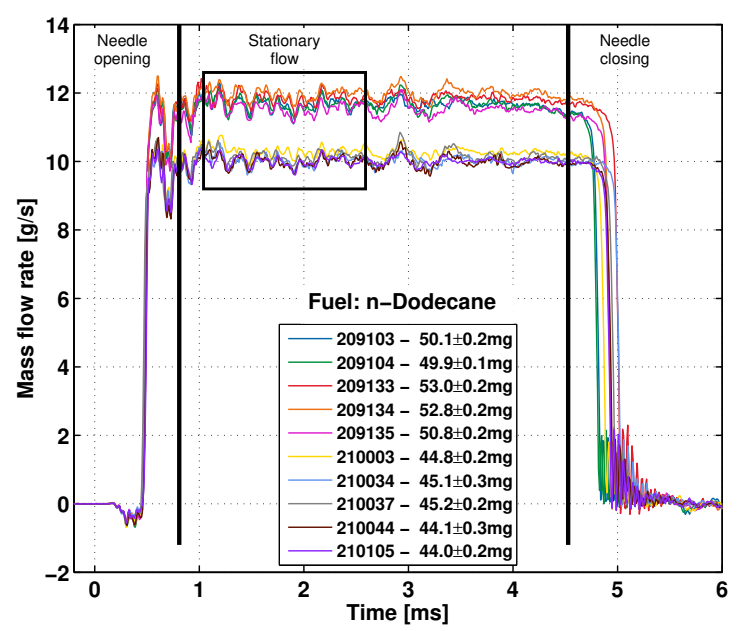

Figure 3: Rate of injection profiles for all "Spray C" and "Spray D" injectors indicating the transient stages and the period selected to calculate the average values. $E T=2.5 \mathrm{~ms} ; p_{i}=150 \mathrm{MPa} ; p_{b}=6 \mathrm{MPa}$.

Table 4: Summary of the geometrical and hydraulic characterization for the n-dodecane tests. $E T=2.5 \mathrm{~ms} ; p_{i}=150 \mathrm{MPa}$; $p_{b}=6 \mathrm{MPa}$.

\begin{tabular}{cc|cc|c}
\hline Injector & $\begin{array}{c}\text { Nozzle outlet } \\
\text { diameter }[\mu \mathrm{m}]\end{array}$ & $\begin{array}{c}\text { Steady-state mass } \\
\text { flow }[\mathrm{g} / \mathrm{s}]\end{array}$ & $\begin{array}{c}\text { Injected mass } \\
{[\mathrm{mg} / \mathrm{st}]}\end{array}$ & $\begin{array}{c}\text { Steady-state } \\
\text { momentum flux }\end{array}$ \\
\hline 103D & 192 & 11.66 & $50.1 \pm 0.2$ & 6.81 \\
104D & 193 & 11.62 & $49.9 \pm 0.1$ & 6.90 \\
133D & 193 & 11.81 & $53.0 \pm 0.2$ & 6.87 \\
134D & 191 & 11.95 & $52.8 \pm 0.2$ & 6.91 \\
135D & 190 & 11.49 & $50.8 \pm 0.2$ & 6.61 \\
\hline Average & $\mathbf{1 9 2}$ & 11.71 & $51.3 \pm 0.2$ & 6.82 \\
\hline 003C & 212 & 10.26 & $44.8 \pm 0.2$ & 5.75 \\
034C & 214 & 10.00 & $45.1 \pm 0.3$ & 5.60 \\
037C & 208 & 10.10 & $45.2 \pm 0.2$ & 5.66 \\
044C & 215 & 9.96 & $44.1 \pm 0.3$ & 5.66 \\
105C & 215 & 9.98 & $44.6 \pm 0.2$ & 5.59 \\
\hline Average & $\mathbf{2 1 3}$ & 10.06 & $44.6 \pm 0.2$ & 5.65 \\
\hline
\end{tabular}




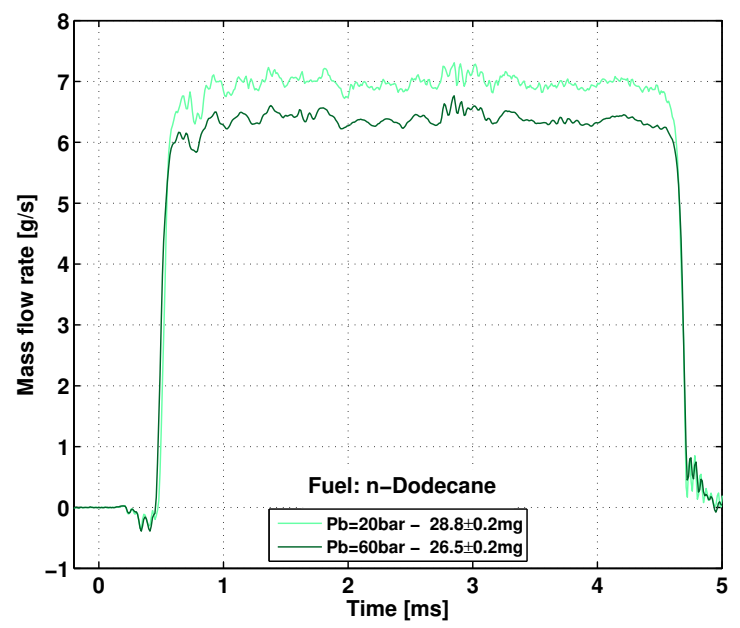

Figure 4: Effect of different chamber pressures on total injected mass. Nozzle 209104; $E T=2.5 \mathrm{~ms} ; p_{i}=50 \mathrm{MPa}$.

\subsubsection{Influence of injection pressure}

The pressure provided by the high-pressure pump of the common-rail system can be regulated by means of a PID controller actuating upon a flow regulation valve in the rail.

In Figure 5, three different injection pressures are depicted for the same electric pulse and back pressure. An increase of injection pressure results in an important increase of mass flow rate. The main reason for that is the increase on effective velocity of the fuel due to the pressure drop in the nozzle. However, further motivation for this observation will be given together with analysis of the flow coefficients.

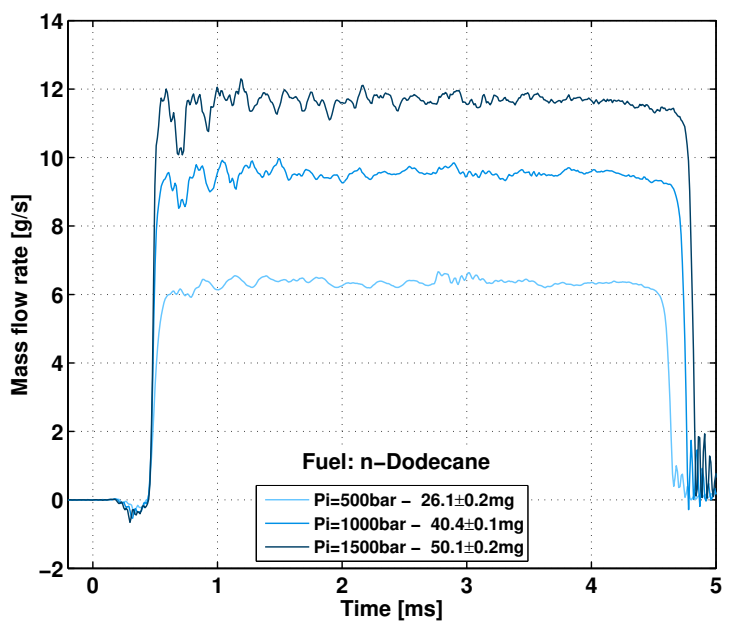

Figure 5: Effect of different injection pressures on total injected mass. Nozzle 209103; $E T=2.5 \mathrm{~ms} ; p_{b}=6 \mathrm{MPa}$.

It is worth to mention that for the same incremental step in injection pressure, the mass flow rate does not increase in the same fraction as the injection pressure increases. This is due to the effective velocity of the fuel approximating to the maximum theoretical Bernoulli's velocity. 


\subsubsection{Samples dispersion}

In order to validate the robustness and repeatability of the employed experimental arrangements, the results from the different injectors and for different tests are compared here.

Closing times. In order to calculate the dispersion on the closing time for the different injectors, the time at which the mass flow rate has decreased to a $20 \%$ of the steady state value has been acquired for each injector.

In Figure 6, can be seen that the "Spray D" injectors show a wider dispersion from nozzle to nozzle as can be demonstrated with the standard deviation. While injectors 134D and 135D close at around the average time, injectors 103D and 104D show an early closing and nozzle 133D, a delayed one.

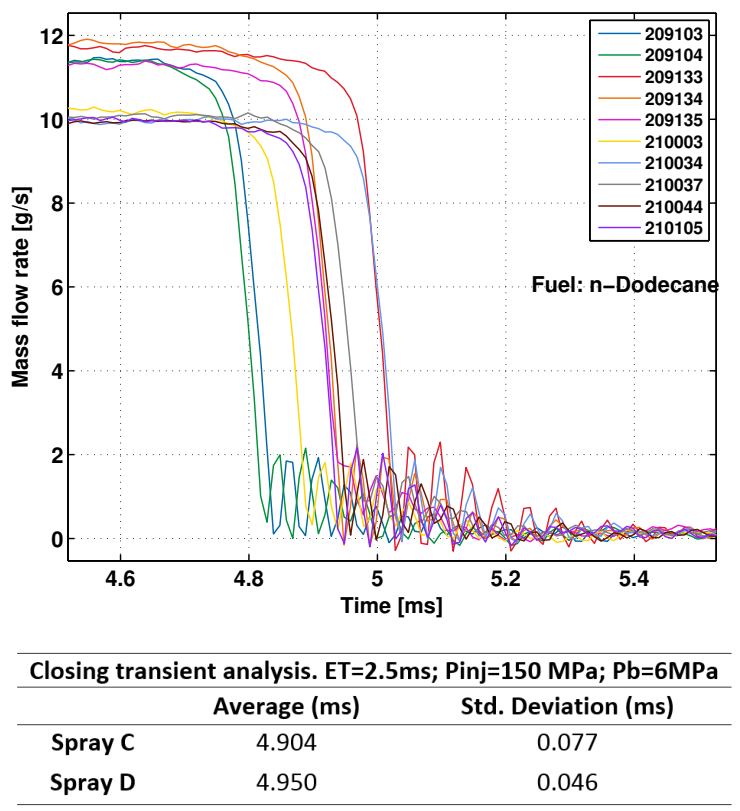

Figure 6: Detail of needle closing behavior for all "Spray C" and "Spray D" nozzles. ROI test ET=2.5 ms; $p_{i}=150 \mathrm{MPa}$; $p_{b}=6 \mathrm{MPa}$.

Similarly, injectors $037 \mathrm{C}, 044 \mathrm{C}$ and $105 \mathrm{C}$ reach $20 \%$ of the steady value at around the average time with injector $003 \mathrm{C}$ closing earlier and $034 \mathrm{C}$ closing later.

Shot-to-shot. As explained before, in order to compute the injection traces shown up to this point, an average of multiple injection events is done (50 for ROI, 25 for momentum flux). However, it is interesting to know how different each injection event is from one another. For that purpose, the relative standard deviation has been calculated and is presented in Figure 7 for the 50 injection events of the ROI tests specified in Table 2.

As can be seen, the dispersion of the points with lower pressure drop is higher. However, the maximum relative standard deviation is around $2 \%$, demonstrating the capability of the common-rail injection system to constantly supply high-pressure fuel with similar characteristics.

The most reliable hypothesis for the higher dispersion for lower pressure drops is the slow motion of the needle lift during the transient regime. In such pressure conditions, the flow restrictions created by the needle due to the increased duration of the transient event originate appreciable differences from injection to injection.

\subsection{Momentum flux rate results}

The spray momentum flux profiles, displayed in Figure 8 are similar to the ROI traces already shown in Figure 3; hence also matching the momentum results to the difference between the outlet diameters of the 


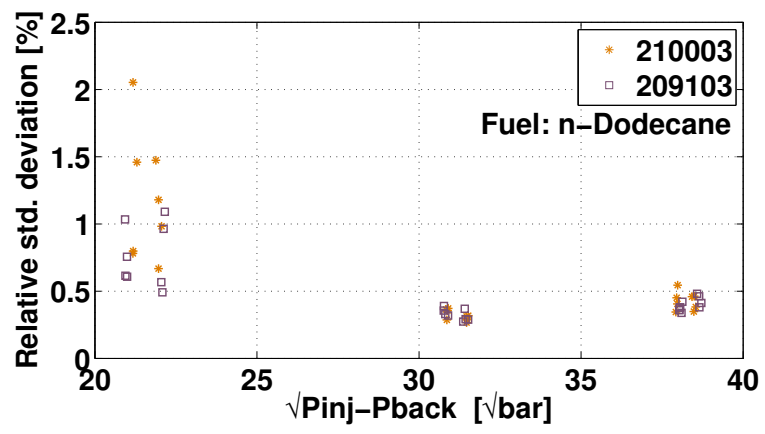

Figure 7: Relative standard deviation of all ROI tests with n-dodecane for injectors 103D and 003C versus the root square of the pressure drop

$\mathrm{C}$ and D nozzles. With respect to the opening and closing slopes, the results show again similar opening slopes but different closing transients amongst the injectors.

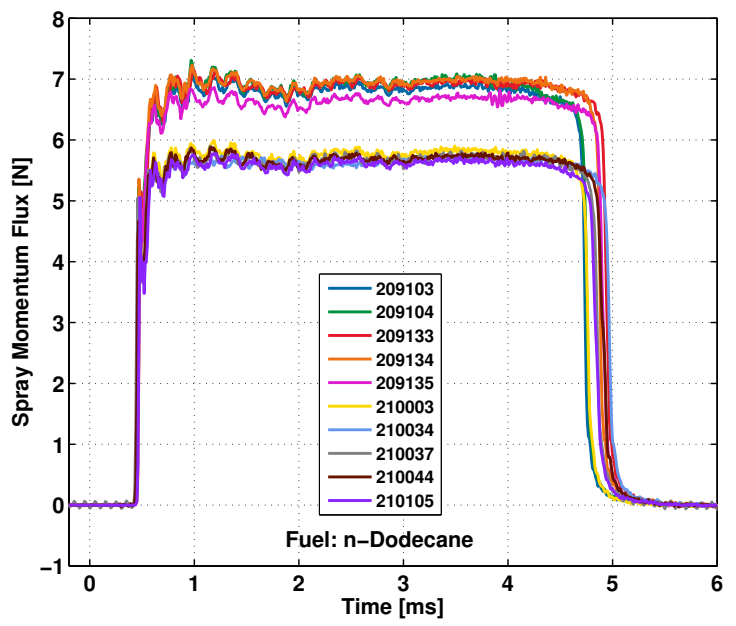

Figure 8: Momentum flux rate profiles for all "Spray C" and "Spray D" injectors. $E T=2.5 \mathrm{~ms} ; p_{i}=150 \mathrm{MPa} ; p_{b}=6 \mathrm{MPa}$.

In accordance with the obtained ROI measurements, "Spray D" injectors provide a greater recording of momentum flux rate during steady state. The stabilized values in the selected steady period are summarized in Table 4.

\subsubsection{Influence of back pressure}

Similarly to what happened for the ROI traces, the momentum flux rate is slightly higher for lower back pressures as can be seen in Figure 9. The reason for that is the reduction of the density in the discharge chamber for lower back pressures. The measured forces become higher for lower densities due to an increase of spray's velocity.

\subsubsection{Influence of injection pressure}

In that case, the conclusion is quite simple. If the injection pressure is increased, the fuel velocity will be as well increase. Accordingly, an increase in velocity will lead to an increase of fuel's momentum that is registered by the force sensor. That phenomenon is demonstrated by the results shown in Figure 10. 


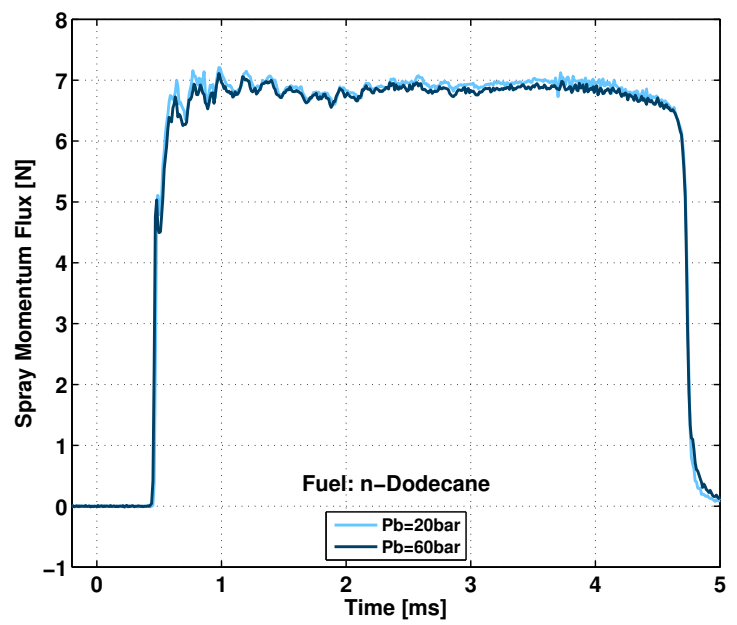

Figure 9: Effect of chamber pressure on spray momentum flux rate. Nozzle 209103; $E T=2.5 \mathrm{~ms} ; p_{i}=150 \mathrm{MPa}$.

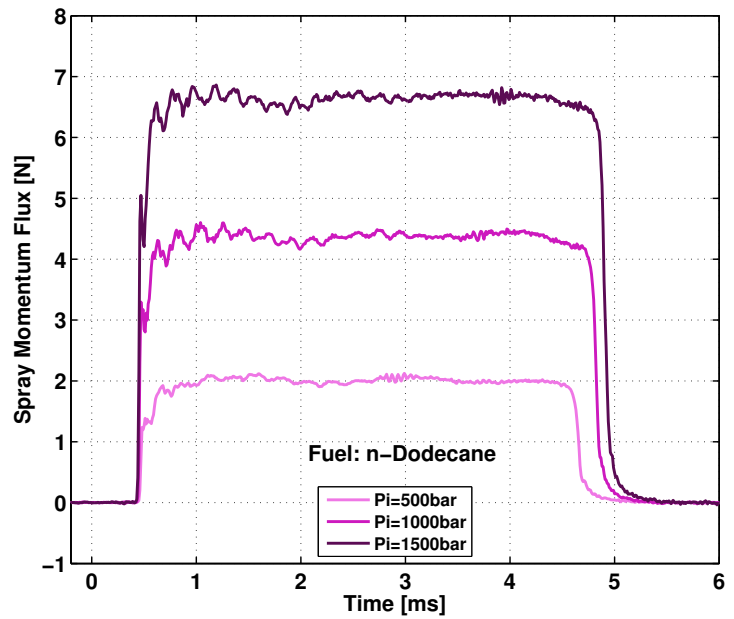

Figure 10: Effect of injection pressures on spray momentum flux rate. Nozzle 209135; $E T=2.5 \mathrm{~ms} ; p_{b}=6 \mathrm{MPa}$. 
Equivalently to the proportionality relation made for the ROI traces, the momentum flux increases when the difference between injection and chamber pressures increases.

\subsection{Comparison on the effect of fuel}

Figure 11 shows the mass flow rate curves using n-dodecane and commercial diesel. Comparing all the curves, a slight increase in mass flow rate and total injected mass with diesel fuel is observed. These results are in agreement with the fuel properties (density and viscosity) presented in Figure 2. Nevertheless, the observed differences can be mainly attributed to the influence of density.

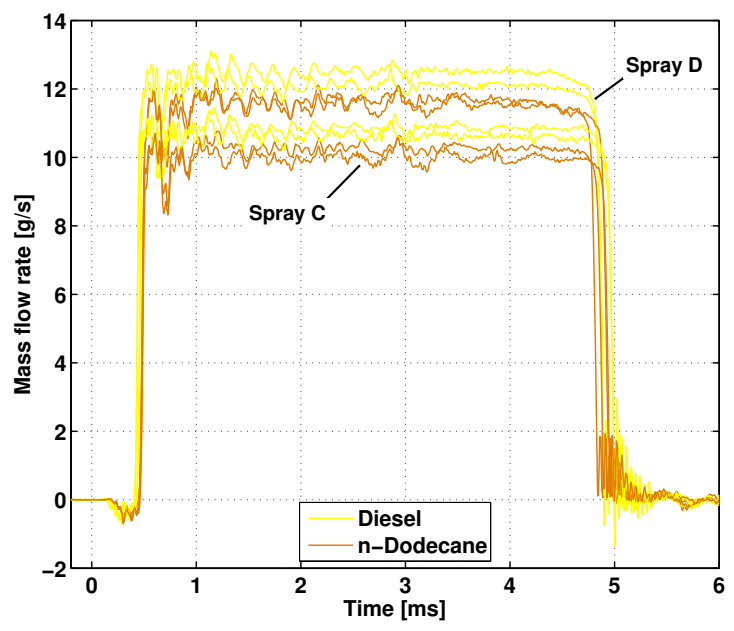

Figure 11: Comparison of mass flow rate profiles using different fuels. $E T=2.5 \mathrm{~ms} ; p_{i}=150 \mathrm{MPa} ; p_{b}=6 \mathrm{MPa}$.

The mass flow rate is proportional to the square root of fuel density. As can be calculated from Figure 2, at $70^{\circ} \mathrm{C}$, a change of fuel (from dodecane to diesel) causes an increase of $12.7 \%$ in the density value, and consequently, this contributes to an increase of injected total mass in percentages of $9.8 \%, 4.9 \%, 8.9 \%$, and $8.6 \%$ for the injectors 103D, 135D, 003C and 044C, respectively. Figure 12 presents the same comparison for the momentum flux rate.

\subsubsection{Effect on transient behavior}

Figures 13 and 14 zoom in on the ROI traces showing more details of the dispersion between the opening and closing slopes. On one hand, it is possible to identify an important difference between diesel and ndodecane for the hydraulic delay. Due to the lower viscosity values of diesel, the fuel propagates into the IRDCI chamber faster than using n-dodecane. However, the slopes remain identical for all injectors and tested conditions. On the other hand, the dispersion in the closing transient is important and no defined trends or patterns can be identified.

\subsection{Effects of cavitation in the nozzle orifice}

Figure 15 shows the time-averaged values of the steady state mass flow rate [13] versus the square root of the pressure difference for the injectors 103D, 135D, 003C and 044C. Experimental test points are spread in four groups of six points each. A single group corresponds to an injection pressure (50, 100,150 and $200 \mathrm{MPa})$ and each point in the same group corresponds to a different back pressure $(2,5.3,6,8.5,9.7,12$ and $14 \mathrm{MPa}$ ).

In the "Spray D" injectors (103D and 135D, conical nozzles), the mass flow rate increases lineally with the square root of the pressure and there is no choking, which indicates that cavitation phenomenon does not appear, even for the highest pressure conditions. On the other hand, in the "Spray C" injectors (003C 


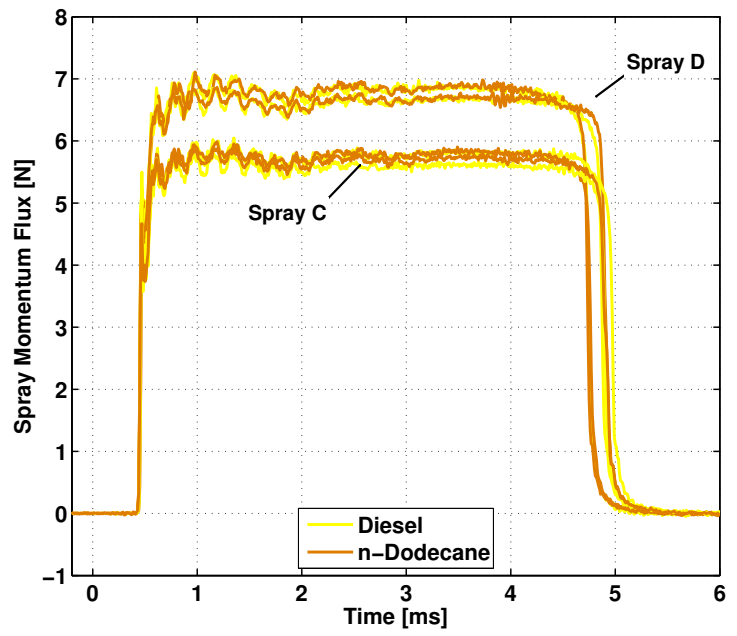

Figure 12: Comparison of momentum flux rate profiles for different fuels. $E T=2.5 \mathrm{~ms} ; p_{i}=150 \mathrm{MPa} ; p_{b}=6 \mathrm{MPa}$.

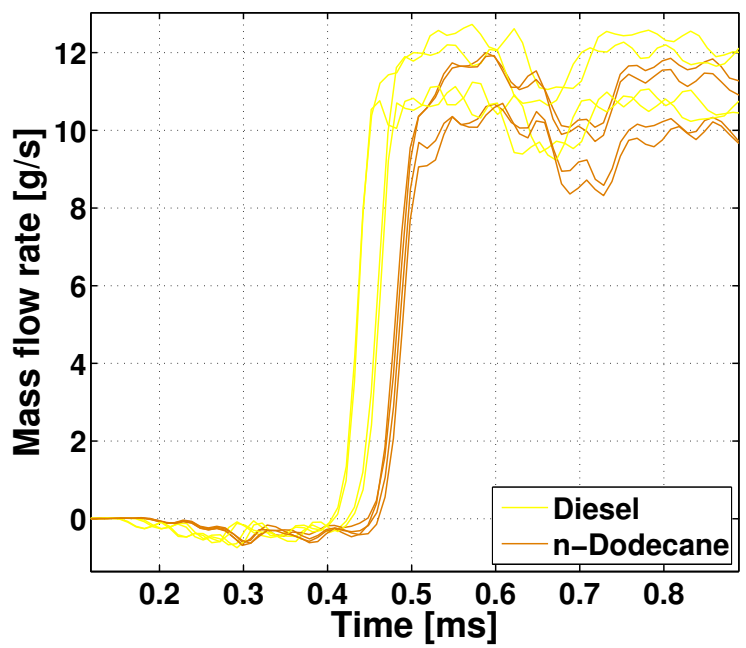

Figure 13: Detail of needle opening behavior for "Spray C" and "Spray D" nozzles. $E T=2.5 \mathrm{~ms} ; p_{i}=150 \mathrm{MPa} ; p_{b}=6 \mathrm{MPa}$. 


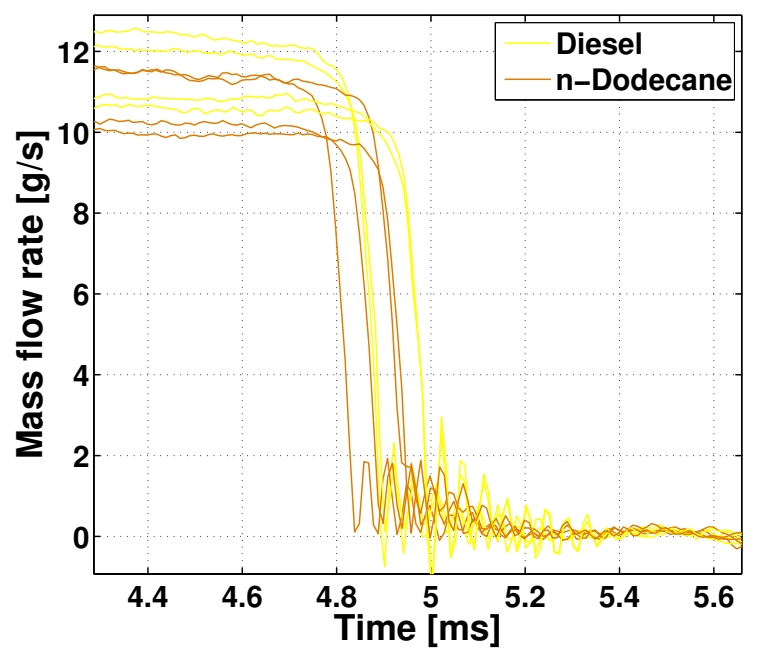

Figure 14: Detail of needle closing behavior for "Spray C" and "Spray D" nozzles. $E T=2.5 \mathrm{~ms} ; p_{i}=150 \mathrm{MPa} ; p_{b}=6 \mathrm{MPa}$.

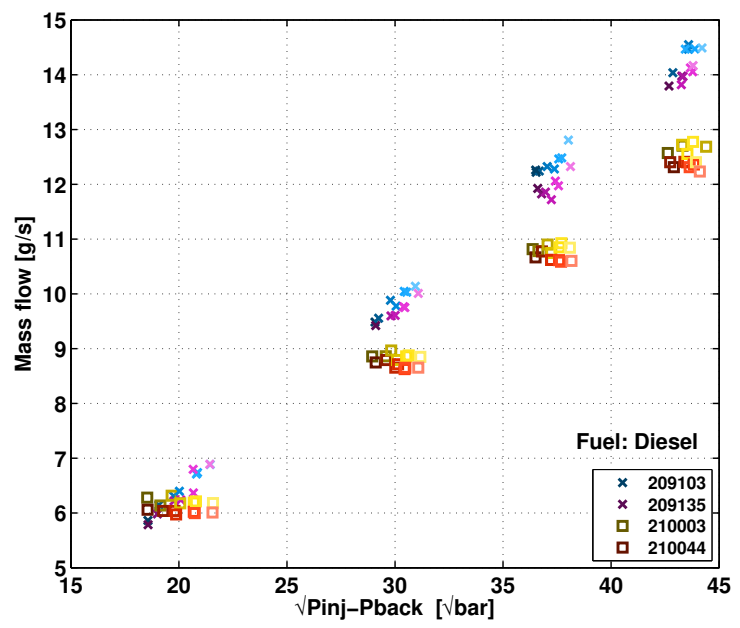

Figure 15: Time-averaged values of the steady state mass flow for C and D nozzles. ET $=2.5 \mathrm{~ms}$ 
and $044 \mathrm{C}$, cylindrical nozzles) the results show that the mass flow is choked for all injection pressures, as most of the points lie on horizontal lines.

If injectors are compared, it is noted that all injectors present a similar value of mass flow at lower injection pressure (50 MPa) and high back pressures (8.5, 9.7, 12 and $14 \mathrm{MPa})$, even with a trend to decrease the mass flow for non-cavitating injectors (103D and 135D) when the back pressure is higher than $12 \mathrm{MPa}$.

Further analysis on the results leads to the study of the discharge coefficient behavior. Figure 16 displays this parameter for both injector types versus the square root of the pressure difference, $\sqrt{\left(p_{i}-p_{b}\right)}$.

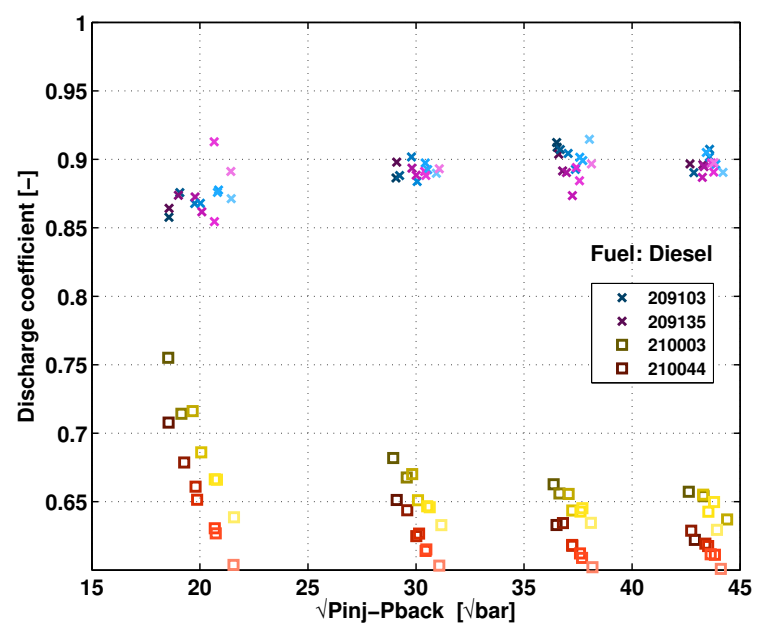

Figure 16: Discharge coefficient versus the square root of the pressure drop for all the tested conditions. $E T=2.5 \mathrm{~ms}$

For the injectors 103D and 135D, the discharge coefficient increases when the square root of the difference pressure and the Reynolds number increases. Due to non-cavitating behavior, values of $C_{d}$ are always higher than the values obtained for the cylindrical nozzles (003C and 044C), with a trend to increase (up to an asymptotic maximum value) with the $\sqrt{\left(p_{i}-p_{b}\right)}$ and $R e$. The increment of $C_{d}$ with the pressure drop in non-cavitating conditions has already been observed by many researches in literature $[15,13,13,16,17]$.

For injectors $003 \mathrm{C}$ and $044 \mathrm{C}$, the discharge coefficient presents a noticeable reduction when $\sqrt{\left(p_{i}-p_{b}\right)}$ increases. This decrease of $C_{d}$ is related to the mass flow collapse due to cavitation phenomenon identified in Figure 15.

Figure 17 shows the time-averaged values of the steady state momentum flux versus the square root of the difference pressure for the injectors 103D, 135D, 003C and 044C. It is noted that, opposite to mass flow, momentum flux does not present any collapse for the cavitating nozzles (003C and 044C). As in the conical nozzles (103D and 135D), this parameter is always proportional to $\sqrt{\left(p_{i}-p_{b}\right)}$, and hence, it does not seem to be affected by cavitation upstream of the nozzle [13].

Comparing the momentum flux of the four injectors, it can be seen that momentum flux for "Spray D" injectors is always higher than for "Spray C" injectors. At lower injection pressure $\left(p_{i n j}=50 \mathrm{MPa}\right)$, differences between both injector types are minor. Also, as injection pressure increases, the momentum flux of injectors $103 \mathrm{D}$ and $003 \mathrm{C}$ is slightly higher than $135 \mathrm{D}$ and $044 \mathrm{C}$, respectively.

Finally, the same behavior followed by the discharge coefficient is found in the momentum coefficient. From Figure 18, it is possible to see how the theoretical values of nominal momentum are not satisfied for "Spray C" injectors and therefore, the coefficients lie between 0.55 and 0.6. This behavior is explained by cavitation. "Spray C" injectors are expected to deliver an important amount of spray momentum due to their wider exit diameter. However, the final effective area is reduced by the restrictions imposed by the vapor bubbles. 


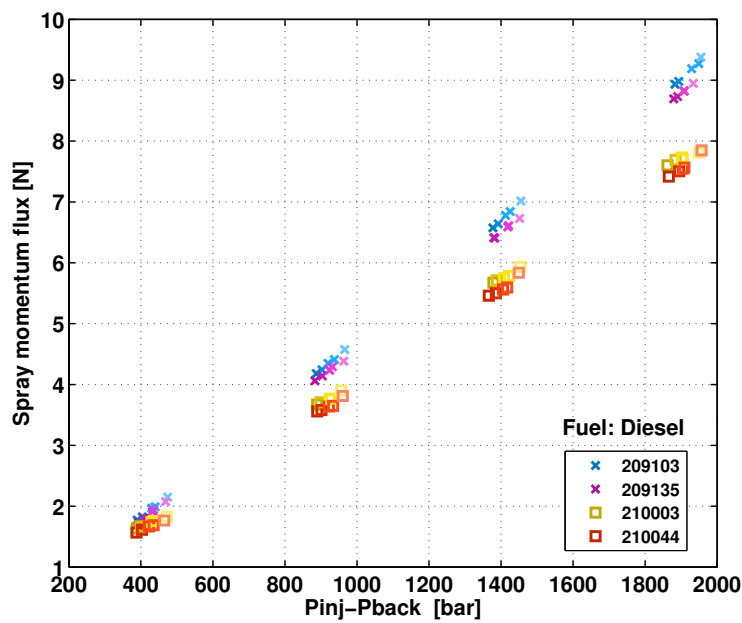

Figure 17: Time-averaged values of the steady state momentum flux for C and D nozzles. $E T=2.5 \mathrm{~ms}$

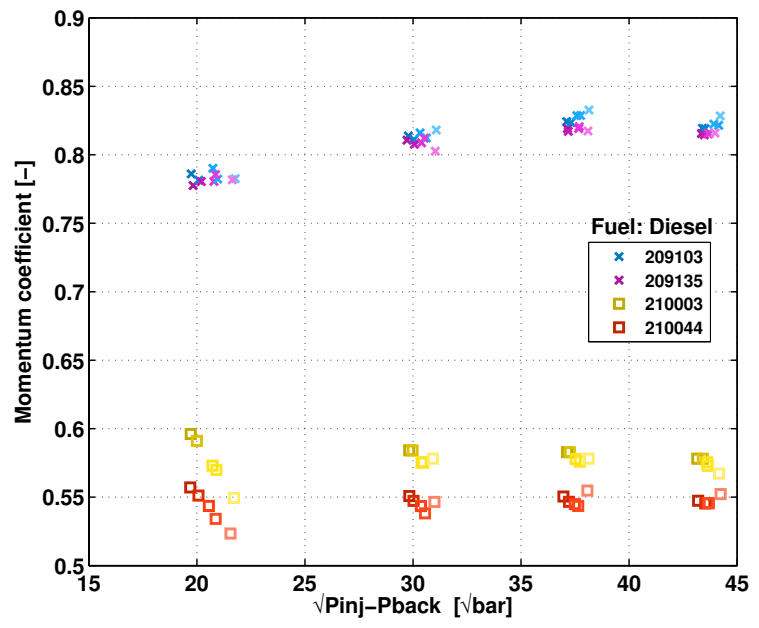

Figure 18: Momentum coefficient versus the square root of the pressure drop for all the tested conditions. $E T=2.5 \mathrm{~ms}$; $p_{i}=150 \mathrm{MPa} ; p_{b}=6 \mathrm{MPa}$. 


\subsection{Flow coefficients}

The fuel outlet velocity is obtained by dividing the momentum flux with the mass flow rate, since other velocity components can be neglected. From Figure 19, it can be noted that the "Spray D" and "Spray C" injectors have similar values of effective velocity and only at lower injection pressure is observed a slightly higher $u_{\text {eff }}$ for 103D and 135D. The most probable explanation for the high effective velocity of injectors $003 \mathrm{C}$ and $044 \mathrm{C}$ (in similar values to $103 \mathrm{D}$ and $135 \mathrm{D}$ ) is that, due to cavitating conditions, the effective diameter of the liquid phase (at orifice outlet section) is reduced, simultaneously to the collapse in mass flow rate as shown in Figures 15 and 16.

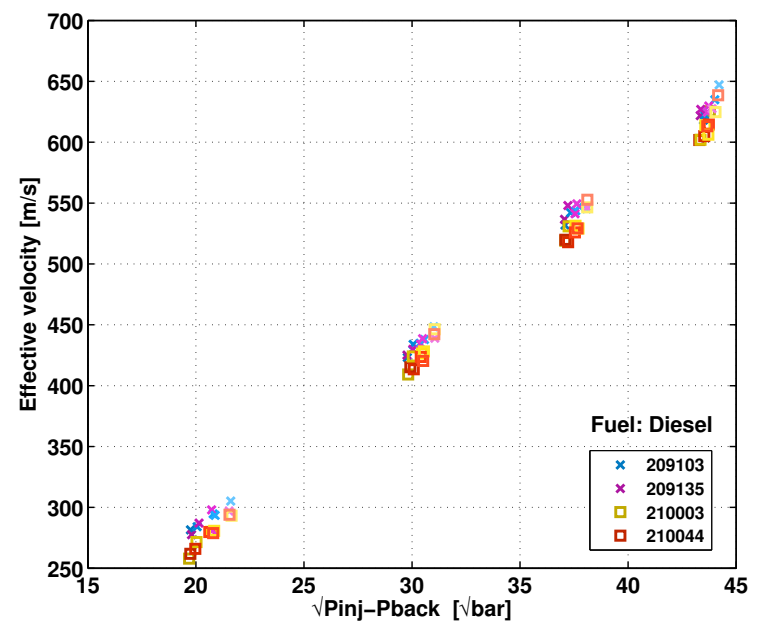

Figure 19: Effective velocity versus the square root of the pressure drop. $E T=2.5 \mathrm{~ms}$

Figure 19 and Figure 20 show the values obtained of effective velocity and diameter. With respect to effective diameter, it can be observed that the values are higher for "Spray D" injectors than "Spray C". However, at lower injection pressure $(50 \mathrm{MPa})$, as back pressure increases, the effective diameter of cavitating injectors ("Spray C") is higher than non-cavitating ones. One explanation for this trend is the mass flow behavior at $50 \mathrm{MPa}$ injection pressure and high back pressures $(>8.5 \mathrm{MPa})$ observed in Figure 15 . However, further investigations are required to give an explanation on this higher mass flow at cavitating conditions, when compared to non-cavitating flows on any experimental conditions.

In Figure 21 and Figure 22, the velocity and area coefficients have been plotted for the four injectors. These coefficients have been calculated based on the $C_{d}$ values. The velocity coefficients, $C_{v}$, of nozzles 103D and $135 \mathrm{D}$ are higher than $003 \mathrm{C}$ and $044 \mathrm{C}$. Furthermore, as expected, the cavitation phenomenon results in a significant reduction of area coefficient, $C_{a}$, due to the appearance of vapor bubbles at the orifice section. The values of $C_{a}$ indicate the reduction in cross-section and/or density at the orifice outlet section. For non-cavitating injectors (103D and 135D), the tendency of $C_{a}$ is around 1 since the liquid-phase occupies all the outlet section. Nevertheless, as occurred to the effective diameter (Figure 20), the tendency of $C_{a}$ is to increase at lower injection pressures and together with the increase in back pressure.

\section{Conclusion and further work}

The characterization of 5 cylindrical ("Spray C") and 5 conical ("Spray D") nozzle injectors at different experimental conditions, including the "Spray A" condition, has led to the following conclusions:

- The outlet diameter of all nozzles of "Spray C" injectors is more than the $200 \mu \mathrm{m}$ nominal specification, as well as for "Spray D" injectors is more than the $180 \mu \mathrm{m}$. The higher variation $(15 \mu \mathrm{m})$ between 


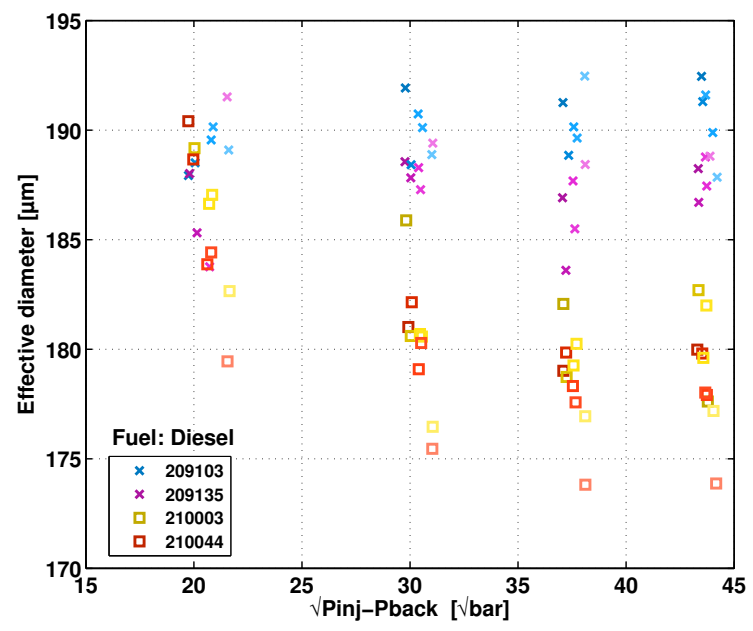

Figure 20: Effective diameter versus the square root of the pressure drop. $E T=2.5 \mathrm{~ms}$

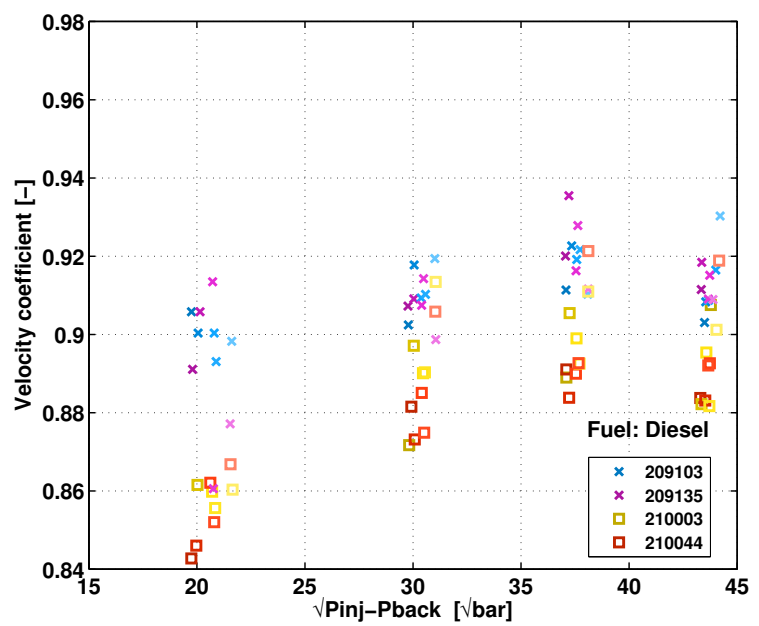

Figure 21: Velocity coefficient versus the square root of pressure drop for all tested conditions. $E T=2.5 \mathrm{~ms}$ 


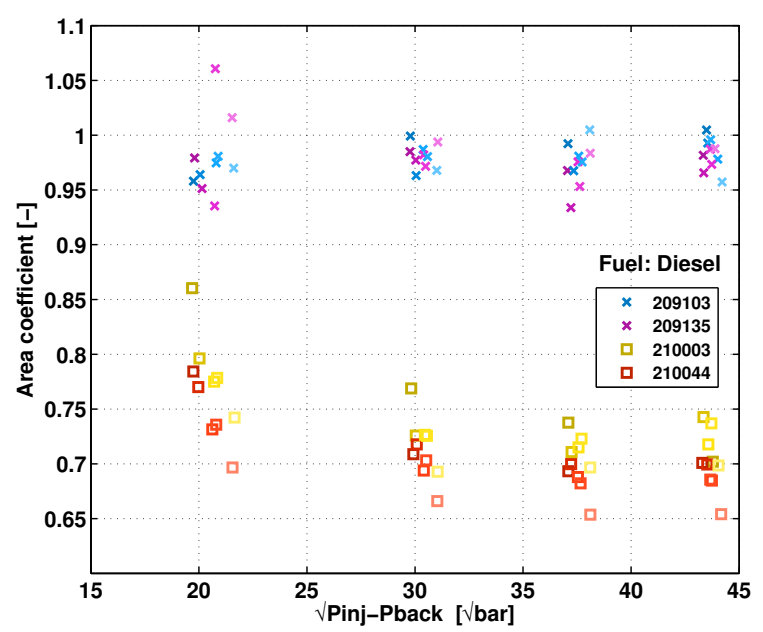

Figure 22: Area coefficient versus the square root of pressure drop for all the tested conditions. $E T=2.5 \mathrm{~ms}$

the calculated diameters and the nominal value of the different nozzles is obtained for the "Spray C" injectors. Moreover, the outlet boundary deviates somewhat from being circular.

- The hydraulic characterization of the nozzles under "Spray A" conditions shows that, when the measured nozzle outlet geometry is accounted for, all the studied nozzles behave reasonably similarly. Although both nozzle typologies used have similar nominal flow capacity in terms of Bosch flow number and despite outlet diameters of "Spray C" nozzles being larger than "Spray D" ones, the stationary mass flow rate is higher in "Spray D" ones due to non-cavitating operation under all tested conditions.

- For the same injector type (C \& D) and energizing time, slightly different closing times appear probably due to the difference in internal geometry from injector to injector.

- In the cylindrical nozzles ("Spray C" injectors), cavitation was detected by the occurrence of choked mass flow rate, and this results in a noticeable reduction of discharge coefficient when $\sqrt{\left(p_{i}-p_{b}\right)}$ and/or Re increases.

- The conical nozzles ("Spray D" injectors) did not present cavitation, since the mass flow rate increases linearly with the pressure drop or the Reynolds number.

- Cavitation phenomena does not have any effect on momentum flux rate.

- Fuel density has a significant influence on the mass flow rate as have been shown by higher ROIs when using Diesel fuel instead of n-Dodecane. However, further studies are required in order to examine the effects of fuel viscosity on the mass flow rate characteristics.

- The effective velocity increases when cavitation appears due to a reduction on the fuel flow section.

- Finally, the area coefficient experiences a pronounced decrease under cavitating conditions meaning that the effective area for the fuel to flow is noticeably reduced.

\section{Acknowledgements}

This work was sponsored by "Ministerio de Economía y Competitividad" of the Spanish Government in the frame of the Project "Estudio de la interacción chorro-pared en condiciones realistas de motor", 
Reference TRA2015-67679-c2-1-R. Additionally, the hardware used for the project was purchased with funding from Ministerio de economía y competitividad FEDER-ICTS-2012-06. Julio Cuisano E. was financed by a postdoctoral fellowship from Fundación Carolina and Pontífica Universidad Católica del Perú.

\section{References}

[1] Y. Yi, R. Hessel, G. S. Zhu, R. D. Reitz, The influence of physical input parameter uncertainties on multidimensional model predictions of diesel engine performance and emissions, SAE Techncal Paper 2000-01-1178 doi:10.4271/2000-01-1178.

[2] ECN, Engine Combustion Network (2015). URL http://www.sandia.gov/ecn/

[3] J. Benajes, R. Payri, M. Bardi, P. Martí-aldaraví, Experimental characterization of diesel ignition and lift-off length using a single-hole ECN injector, Applied Thermal Engineering 58 (1-2) (2013) 554-563. doi : 10.1016/j.applthermaleng.2013. 04.044 .

[4] M. Meijer, B. Somers, J. Johnson, J. Naber, L. M. Malbec, G. Bruneaux, L. M. Pickett, M. Bardi, R. Payri, T. Bazyn, Engine Combustion Network (ECN): Characterization and comparison of boundary conditions for different combustion vessels, Atomization and Sprays 22 (9) (2012) 777-806. doi:10.1615/AtomizSpr.2012006083.

[5] A. L. Kastengren, Z. Tilocco, C. F. Powell, L. M. Pickett, R. Payri, T. Bazyn, Engine Combustion Network (ECN): Measurements of nozzle geometry and hydraulic behavior, Atomization and Sprays 22 (12) (2012) 1011-1052. doi: 10.1615/AtomizSpr. 2013006309.

[6] J. M. Desantes, J. V. Pastor, R. Payri, J. M. Pastor, Experimental characterization of internal nozzle flow and diesel spray behavior. Part II: Evaporative conditions, Atomization and Sprays 15 (5) (2005) 489-516. doi:10.1615/AtomizSpr.v15. i5. 20 .

[7] R. Payri, S. Molina, F. J. Salvador, J. Gimeno, A study of the relation between nozzle geometry, internal flow and sprays characteristics in diesel fuel injection systems, KSME International Journal 18 (7) (2004) 1222-1235. doi:10.1007/ BF02983297.

[8] C. Soteriou, S. Zuelch, M. Lambert, D. Passerel, The flow characteristics of high efficiency diesel nozzles with enhanced geometry holes (2006)

[9] R. Payri, F. J. Salvador, J. Gimeno, G. Bracho, A new methodology for correcting the signal cumulative phenomenon on injection rate measurements, Experimental Techniques 32 (1) (2008) 46-49. doi:10.1111/j.1747-1567.2007.00188.x.

[10] N. I. of Standards, Technology, NIST chemistry webbook (2015). URL http://webbook.nist.gov/chemistry/

[11] Eurostat, Energy, transport and environment indicators - 2015 edition, Publications Office of the European Union, Luxembourg, 2015. doi:10.2785/547816.

[12] ASTM, ASTM D1298-12b, Standard test method for density, relative density, or API gravity of crude petroleum and liquid petroleum products by hydrometer method (2012). doi:10.1520/D1298-12B.

[13] R. Payri, J. M. García, F. J. Salvador, J. Gimeno, Using spray momentum flux measurements to understand the influence of diesel nozzle geometry on spray characteristics, Fuel 84 (5) (2005) 551-561. doi:http://dx.doi.org/10.1016/j.fuel. 2004.10.009.

[14] R. Payri, H. Climent, F. J. Salvador, a. G. Favennec, Diesel Injection System Modelling. Methodology and Application for a First-generation Common Rail System, Proceedings of the Institution of Mechanical Engineers, Part D: Journal of Automobile Engineering 218 (1) (2004) 81-91. doi:10.1243/095440704322829191.

[15] C. Soteriou, R. Andrews, M. Smith, Direct injection diesel sprays and the effect of cavitation and hydraulic flip on atomization, SAE Technical Paper 950080 doi:10.4271/950080.

[16] R. Payri, F. J. Salvador, J. Gimeno, L. D. Zapata, Diesel nozzle geometry influence on spray liquid-phase fuel penetration in evaporative conditions, Fuel 87 (7) (2008) 1165-1176. doi:http://dx.doi.org/10.1016/j.fuel.2007.05.058.

[17] A. Lichtarowicz, R. K. Duggins, E. Markland, Discharge coefficients for incompressible non-cavitating flow through long orifices, Archive: Journal of Mechanical Engineering Science 1959-1982 (vols 1-23) 7 (2) (1965) 210-219. doi:10.1243/ JMES_JOUR_1965_007_029_02. 